\title{
Dose-Dependent Effects of Multiple Acute Cocaine Injections on Maternal Behavior and Aggression in Sprague-Dawley Rats
}

\author{
Josephine M. Johns, Christina J. Nelson, Kathleen E. Meter, Deborah A. Lubin, C. Destine \\ Couch, Andy Ayers, and Cheryl H. Walker \\ Departments of Psychiatry and Psychology, University of North Carolina, Chapel Hill, N.C., USA
}

\begin{abstract}
Rat dams, which had no prior drug treatment, were either nontreated controls or were injected subcutaneously 4 times during a 10-day period with a single dose of 30,15 or $7.5 \mathrm{mg} / \mathrm{kg}$ of cocaine hydrochloride $\mathrm{HCl}$, or normal saline. Injections were given immediately postpartum following delivery of their final pup (PPD 1), and again on postpartum day 3 (PPD 3), postpartum day 6 (PPD 6) and postpartum day 10 (PPD 10). Dams were observed 30 min following injections for maternal behavior (MB) towards 8 surrogate male pups on PPD 1 and PPD 3 and for aggression towards a male or female intruder in the presence of their litter on PPD 6 and PPD 10. Compared to saline and untreated controls, cocaine-treated dams exhibited more disruptions in MB on both PPD 1 and PPD 3 and were less aggressive towards an intruder, regardless of intruder sex, on PPD 6 and PPD 10. In most cases MB was altered in a dose-dependent manner with the higher doses of cocaine resulting in a greater disruption of behavior.
\end{abstract}

\section{Keywords}

Cocaine; acute; Maternal behavior; Maternal aggression; Hyperactivity

\section{Introduction}

Recently, it was reported that cocaine-abusing mothers were less interactive with their children than mothers who were not abusing cocaine, as evidenced by a lack of attentive behaviors and an inability to focus attentions towards their child [1]. This report is consistent with previous reports that maternal neglect and child abuse are frequently correlated with maternal cocaine use during and following pregnancy [2-5]. Studies of maternal cocaine abuse in the human population have been confounded by polydrug abuse, variable routes of administration health and socioeconomic variables and ethical considerations. Several animal models have been developed over the past few years to control for these variables and to allow researchers to examine some of the underlying biochemistry associated with cocaine-related changes in maternal behavior [6-9].

There are been several reports concenring the effects of chronic gestational cocaine treatment on maternal behavior in rats, each of which employed different behavioral and dosing paradigms [6-10]. Despite the differences in methodology, the reports generally indicate that chronic gestational cocaine at doses of around $20-30 \mathrm{mg} / \mathrm{kg}$ and higher (depending on the route of administration) disrupts the onset of pup-directed maternal 
behavior in rats, but has relatively little effect on pup-directed maternal behaviors (other than maternal aggression) once they have become established. The distinction between the onset and maintenance periods of maternal behavior is particularly important because these two periods are apparently regulated by different underlying hormonal states (oxytocin is essential for the normal onset of maternal behavior but not essential for its maintenance once maternal behavior is established) which may be differentially altered by cocaine [11-19]. Maternal aggression towards a male or female intruder has been found to be increased in rat dams beginning around postpartum day (PPD) 6 and continuing until at least PPD 10, following chronic gestational treatment with $30-40 \mathrm{mg} / \mathrm{kg}$ of cocaine compared with controls [6, 20-22].

While there have been a number of reports to date concerning chronic cocaine treatment and maternal behavior, there have been fewer animal studies which employed acute cocaine treatment paradigms. Those studies have reported impairment of several maternal behaviors (nestbuilding, crouching, retrieval, licking, grouping) following injection with one or perhaps two doses of cocaine at the onset [20] or later in the postpartum period when maternal behavior should be established [7, 23]. There are no published papers of which we are aware that have used systematic detailed measures of maternal behavior and aggression, following acute, multiple doses of cocaine over a prolonged lactation period. The present study was designed to determine the effects of multiple doses of cocaine given acutely, on the onset and maintenance of maternal behavior and on maternal aggression towards an intruder using a previously described behavioral testing paradigm, which has proven informative following chronic cocaine treatment [20-22].

We now report that acute cocaine treatment dose-dependently alters both the onset and maintenance of maternal behavior and, unlike chronic cocaine, significantly reduces maternal aggression towards male and female intruders on PPD 6 and 10.

\section{Methods}

\section{Subjects and Treatment}

Gravid, nulliparous Sprague-Dawley rats (Charles River, Raleigh, N.C., USA), were randomly assigned to one of four treatment groups or as a control or surrogate dam (no treatment) the morning a sperm plug was found (designated as gestational day 0). Dams were housed singly in plastic cages on a 12-hour light : 12-hour dark cycle with the light period beginning at 09.00. Surrogate and treatment dams had free access to food and water. Dams were weighed every 3 days. Dams received no treatment until immediately following delivery of their final pup. All pups were then removed, sexed and weighed. Treatment dams then received one subcutaneous injection of either 30,15 or $7,5 \mathrm{mg} / \mathrm{kg}$ of cocaine- $\mathrm{HCl}$ (Sigma Chemical Co., St. Louis, Mo., USA) in a distilled water solution or an equal volume of $(0.9 \%)$ normal saline (saline). Controls received no injection but were otherwise treated exactly like treatment dams.

\section{Procedures}

Maternal Behavior-Observations were made in a room with low ambient lighting. Following the injections (or handling for controls), each dam remained alone in its cage for $30 \mathrm{~min}$. A surrogate litter of 8 male pups (born within the previous $1-6 \mathrm{~h}$ and nesting material (10 strips of clean paper towel) were then placed in the dam's cage. The nesting material was placed beside the dam and the 8 pups were placed at the opposite end of the cage from the dam. Behavior was videotaped with a Panasonic VHS video camera with low light sensitivity for a 30-min period beginning at the moment the pups were placed with the dam. Following the test period, dams ad their surrogate litters were returned to the colony 
room. Subjects were observed daily to ascertain if dams were feeding and caring for (keeping warm, licking) their pups until testing for established maternal behavior on PPD 3 . The test procedure was the same on PPD 3 except the surrogate litter was removed and weighed before the dams were injected, and then 30 min following the injection, the same surrogate litter was placed with the same dam along with new nesting material. After testing, the dam and her surrogate litter were returned to the colony room until PPD 6 when maternal aggression testing began.

Two independent observers blind to treatment condition scored videotapes using a computerized behavioral program which records frequency, duration and latency for different behaviors. Interrater reliability was $90 \%$ or better on frequency and latency measures and $80 \%$ or better on duration scores. Behaviors of the dam which were scored included: retrieval of 2, 6 and 8 pups (dam is scored as retrieving a pup when she transports the pup by mouth to the nest), nestbuild (moving, mouthing or arranging paper), crouch (dam stands over all or most of the pups with a pronounced dorsal arch with rigid leg support, legs usually splayed), self-groom, rest/lay (dam lays flat on top of or away from pups), lick pups, sniff/touch (dam sniffs or touches at least one pup with her snout or paw), rear/sniff (dam rears on her hind legs or sniffs the cage or air) and other, a category for any other behavior which might occur.

Maternal Aggression-On PPD 6 and PPD 10, each dam with its surrogate litter was brought to the observation room, in their home cage. Dams were weighed, and the pups were removed and weighed while the treatment dams were injected with their respective dose of cocaine. After the dams were injected (or weighed as were untreated controls) the pups were returned and the dam and their litters remained in the cage for a 30-min period. After the 30-min period, a male or female intruder rat (intruders were only used once) slightly smaller than the dam, was placed in the opposite end of the cage from the mother and pups. Videotaping of behavior began as soon as the intruder was placed in the cage and continued for a 10-min period. Half of the dams in each treatment or control group received male and half received female intruders on each test day. Aggression testing began by 10.00 a.m. and was concluded by 12.30 p.m. All groups were represented at various times within the testing period. Intruders were permanently removed if the interactions presented a danger to an animal's health or if the intruder attacked the pups, and data for that session were not included in the analyses.

Aggression tapes were scored by 2 independent observers under the same conditions and reliability constrains as for maternal behavior. Frequency, duration, and latency of the following 13 behaviors exhibited by the dam were scored: body block/over (dam places her body between the intruder and pups or stands over pups but does not attack the intruder), front/lateral threat (dam moves toward or stretches her head toward intruder in a 'threatening' manner, putting her snout close to or touching the intruder's face (front threat) or she moves laterally with her body pushing the intruder back or over (lateral threat), roughgroom/nip (dam grooms the intruder roughly generally in the back, neck or genital areas or nips it), aggressive posture (dam stands over the intruder, pushing it down with her front paws or forces the intruder into a prone posture), fight attack (dam jumps on and bites intruder, usually accompanied by rolling and fur pulling), push/box (dam pushes intruder away from her body or boxes intruder with her forepaws), touch/sniff pups (dam touches any pup with nose or paw), rear/sniff (dam rears on her hindlegs or sniffs the cage or air), locomote (dam moves all four paws forward or backward), self-groom, defensive posture (dam assumes submissive posture), make barrier (dam pushes cage bedding into a wall between her litter and the intruder) and other (any other behavior than those listed). If the dam allowed the male to attack her pups it was noted and the session was terminated. 
Oxytocin Radioimmunoassay-On PPD 11 dams were decapitated and the whole amygdala, hippocampus and ventral tegmental area of their brains dissected on ice and weighed for an oxytocin radioimmunoassay. Brains were cut coronally from the ventral side rostral to the optic chiasm (approximately A7100) according to Konig and Klippel [24] and just caudal to the optic chiasm (approximately A5800) to define the preoptic-anterior hypothalamic area, and sectioned once again just caudal to the tuber cinereum (approximately A3800) to define the medial basal hypothalamus. The amygdala was removed from these two sections. The whole hippocampus was then removed from the caudal remainder of the brain, and the ventral tegmental area dissected from this portion by making dorsoventral cuts medial to the optic tracts with a dorsal cut at the ventral extent of the central gray.

Brain tissues were homogenized in cold buffer (19 $\mathrm{m} M$ monobasic sodium phosphate, 81 $\mathrm{m} M$ dibasic sodium phosphate, $0.05 M \mathrm{NaCl}, 0.1 \%$ bovine serum albumin, $0.1 \%$ Triton $\times$ $-100,0.1 \%$ sodium oxide at $\mathrm{pH} 7.4$ ) and centrifuged at 3,000 $\mathrm{g}$ for $30 \mathrm{~min}$. Supernatants were analyzed for oxytocin immunoreactive content according to a protocol from Peninsula Laboratories Inc. (Belmont, Calif., USA) for each brain area/animal. All supplies were obtained from Peninsula Labs. Briefly, oxytocin-like immunoreactivity was assayed by incubating samples and standards $(0.5-500 \mathrm{pg})$ in duplicate for $16-24 \mathrm{~h}$ at $0{ }^{\circ} \mathrm{C}$, with rabbit antioxytocin serum (Peninsula Laboratories, lot No. 023204-2) at a final dilution of 1:39,000. The assay samples and standards were then incubated with ${ }^{125}$ I-oxytocin (specific activity $=12,86 \mathrm{Ci} / \mathrm{mmol}$ ) for $16-24 \mathrm{~h}$ at $0^{\circ} \mathrm{C}$. The bound oxytocin was separated from free by incubating with normal rabbit serum and goat antirabbit IgG serum and centrifugation for $40 \mathrm{~min}$ at 2,500 rpm. Radioactivity was measured by an LKB Clinigamma counter with a data reduction package. Cross-reacitivity of arginine vasopressin and somatostatin was undetectable. The sensitivity of the assay was $7.3 \mathrm{pg} /$ tube. An intra-assay coefficient of variation $(\mathrm{CV})$ of $<5 \%$ and an interassay $\mathrm{CV}$ of $14 \%$ at approximately $50 \%$ binding were determined. Oxytocin levels were analyzed by analyses of variance (ANOVA) followed by post-hoc tests comparing picograms per milligram wet tissue weight between groups.

\section{Statistical Analysis}

Saline and untreated control groups did not vary from each other on any measure and were therefore combined into a single control group (sal/con). ANOVA group (sal/con vs. cocaine three dose levels) by day (PPD 1 vs. PPD 3) for maternal behavior and group [sal/con vs. cocaine (three dose levels)] by day (PPD 6 vs. PPD 10) by intruder sex (male vs. female) for maternal aggression followed by Tukey post-hoc analyses were conducted on the data. ANOVA was also used to assess gestational measures. Group N's varied in the aggression results because test sessions with fights that resulted in serious injuries to pups or intruders were stopped and not included in the final results. The $\mathrm{p}$ values in the figures and tables represent values from Tukey post-hoc analyses and significance was assumed at the 0.05 level or less.

\section{Results \\ Gestational Variables}

There were no significant differences among any of the groups with respect to length of gestation, litter weight, number of pups or total weight gain of the dams over gestation. Cocaine-treated dams in the $30-\mathrm{mg} / \mathrm{kg}$ dose groups lost weight over the 10-day postpartum period $(-4.74 \mathrm{~g})$ as compared to all other treatment and control groups, but the difference was not statistically significant. Although the cocaine-treated dams received only 4 single cocaine injections over the 10-day postpartum period, their surrogate litters were differentially affected. As shown in figure 1, there was a dose-response effect on litter total 
weight gain over the 10-day testing period such that litters from the highest dose groups (30 and $15 \mathrm{mg} / \mathrm{kg}$ ) gained significantly less weight than did the low-dose and control groups $[F(3,46)=7.02, p<0.00]$. Dams and litters were weighed before each test session so the differences were apparent after only 3 injections given to the mother.

\section{Maternal Behavior}

There was a significant group effect on latency to retrieve pups with the $30-\mathrm{mg} / \mathrm{kg}$ dose group taking longer than sal/con to retrieve $2[\mathrm{~F}(3,92)=3.99, \mathrm{p}<0.01], 6[\mathrm{~F}(3,92)=3.42, \mathrm{p}$ $<0.01]$ and 8 pups to the nest $[\mathrm{F}(3,92)=5.47, \mathrm{p}<0.01]$ on PPD 1 and PPD 3 . As shown in figure 2a, there was a dose-response effect on frequency of nestbuilding, crouching and licking pups. The highest dose groups were less likely to lick pups, nestbuild or crouch to feed their pups. Figure $2 b$ indicates that the latency to nestbuild and crouch was increased in cocaine-treated groups in a dose-response manner, with the longest latencies exhibited by the $30-$ and $15-\mathrm{mg} / \mathrm{kg}$ groups. There was a significant interaction effect (group $\times \mathrm{PPD}$ ) on the frequency of rearing and sniffing $[\mathrm{F}(3,92)=4.23, \mathrm{p}<0.01]$. On PPD $3,30-\mathrm{mg} / \mathrm{kg}(\overline{\mathrm{x}}=$ $73)$ and $15-\mathrm{mg} / \mathrm{kg}(\overline{\mathrm{x}}=83)$ cocaine dose groups reared and/or sniffed significantly more often than the sal/con group $(\bar{x}=30, p<0.02)$. There was a twofold increase in rearing and sniffing in sal/con dams and a four- to six-fold increase in cocaine-treated dams on PPD 3 and PPD $1[\mathrm{~F}(3,92)=50.04, \mathrm{p}<0.001$ for duration $]$. There was a group $[\mathrm{F}(3,92=8.41, \mathrm{p}<$ $0.01]$ and session effect $[\mathrm{F}(3,92)=42.30, \mathrm{p}<0.01]$ on the frequency and a group $[\mathrm{F}(3,92)=$ $11.52, \mathrm{p}<0.01]$ and session effect $[\mathrm{F}(3,92)=16,46, \mathrm{p}<0.01]$ on duration of 'other' behaviors. The 30- and $15-\mathrm{mg} / \mathrm{kg}$ cocaine dose groups performed 'other' behaviors more often and for a longer time than did the sal/con group. All dams had a shorter latency $[\mathrm{F}(3,92)=38.11, \mathrm{p}<0.02]$ to begin performing 'other' behaviors during PPD1 ( $\overline{\mathrm{x}}=1.05 \mathrm{~s})$ compared to PPD $3(\bar{x}=2.34 \mathrm{~s})$.

\section{Maternal Aggression}

Figures $3 \mathrm{a}$ and $\mathrm{b}$ illustrate the significant dose-dependent treatment effect on frequency of $[\mathrm{F}(3,60)=4.59, \mathrm{p}<0.01]$ and latency to $[\mathrm{F}(3,60)=13.13, \mathrm{p}<0.01]$ fight attack. Cocainetreated dams fought less and began fighting later than did sal/con dams. The $30-\mathrm{mg} / \mathrm{kg}$ dose group tended to threaten intruders less (nonsignificant trend) and took longer (cocaine, $\overline{\mathrm{x}}=$ $48 \mathrm{~s}, \mathrm{sal} / \mathrm{con}, \overline{\mathrm{x}}=29 \mathrm{~s})$ before beginning to threaten than did sal/con dams $[F(3,60)=5.17, \mathrm{p}$ $<0.01]$. Although sex of the intruder did not alter the threats or attacks made by dams, it did have a significant effect on the measures of push/box, defensive posture and roughgroom/ nip regardless of treatment. All dams had higher frequencies $[F(1,60)=4.89, p<0.01]$ and durations $[\mathrm{F}(1,60)=10.17, \mathrm{p}<0.01]$ of roughgrooming a female than a male intruder. All dams were also quicker to push/box a male than they were a female intruder on PPD 6 $[\mathrm{F}(1,60)=10,49, \mathrm{p}<0.01]$. When a female intruder was introduced into the dam's cage, the dam exhibited longer latencies before assuming a submissive or defensive posture than when a male intruder was placed in the dam's cage $[\mathrm{F}(1,60)=4.61, \mathrm{p}<0.04]$. The duration of time spent doing 'other' behaviors on PPD 6 and 10 was longest in the $30-\mathrm{mg} / \mathrm{kg}$ dose groups than any of the other cocaine-treated or sal/con groups $[F(3,60)=6.26, p<0.01]$. Rearing and sniffing was dose-dependently increased in the cocaine-treated dams compared to sal $/$ con dams $[F(3,61)=9.68, \mathrm{p}<0.01]$. The 30 - and $15-\mathrm{mg} / \mathrm{kg}$ dose groups had a higher frequencey of rear/sniff than sal/con dams and the $30-\mathrm{mg} / \mathrm{kg}$ dose group also had a higher frequency of rearing and sniffing than the $7.5-\mathrm{mg} / \mathrm{kg}$ dose group (fig. 4).

\section{Oxytocin Assay}

There were no significant differences in oxytocin levels between groups for any brain areas on PPD 11. There was a nonsignificant dose-dependent trend such that higher dose groups had higher levels of oxytocin in the amygdala than did the low-dose and sal/con dams. 


\section{Discussion}

Results indicate that acute cocaine treatment in rats, given on PPD 1, 3, 6 and 10, alters both the onset and maintenance of maternal behavior and decreases maternal aggression in a dose-dependent manner. Significant differences in the litter weight gain of acutely treated dams following three single injections of 30 and $15 \mathrm{mg} / \mathrm{kg}$ of cocaine could be the result of several factors. It is possible that cocaine ingested from the mother's milk could have had anorectic effects on the pups or that the dams, which were shown to crouch less following cocaine treatment, fed their litters less often. Oxytocin, which is necessary for ejection of the milk from the mammary glands $[25,26]$, has been reported to be reduced by cocaine treatment [21,27-28]. Cocaine treatment might have reduced production of oxytocin such that the high-dose dams could not eject their milk as easily as control rats. Since all dams were observed to be nursing and maintaining general maternal care, we cannot be certain of the basis for the litter weight reductions. It is perhaps clinically relevant that after 3 single doses of cocaine the pups from the $30-\mathrm{mg} / \mathrm{kg}$ dose cocaine-treated dams could be so significantly affected. Human mothers addicted to cocaine before or during pregnancy may be more likely to abuse cocaine following childbirth, at least casually, than nonaddicted mothers, incorrectly assuming that their babies will not be adversely affected.

There have been other reports on the effects of acute cocaine on maternal behavior [7, 20, 23], but we are aware of only one published abstract that addressed this issue in the depth that the present study has [29]. The authors [29] reported that acute postpartum cocaine treatment in rat dams on PPD 3, 4 and 5 altered all components of established maternal behavior, supporting our present findings. We had previously reported that a single injection of $15 \mathrm{mg} / \mathrm{kg}$ on PPD 1 disrupted many aspects of the onset of maternal behavior and did not increase maternal aggression on PPD 6 [20]. It was clear that a dose-response study was needed to more fully explore the extent of changes found following multiple doses of acute postpartum cocaine injections. Although acute injections immediately following parturition (PPD 1) consistently produce the same replicable disruptions in maternal behavior [20], it must be realized that in the present study dams got a total of 4 injections over the 10-day period. It is possible that sensitization may have occurred and that there were some cumulative effects of the injections, particularly by PPD 6 and 10. It would have been ideal to have separate experimental groups for each postpartum day. In such a design, effects of single cocaine injections on each of the postpartum days could have been compared to the effects we found with multiple injections given over the 10-day period. This would have allowed us to discern differences resulting from the different paradigms. Rat dams were clearly under the direct influence of cocaine as their behavior was tested when levels should have been peaking in their bloodstream (plasma cocaine levels were not determined). We saw a rise in stereotypical behavior (rearing and sniffing) and activity-related behaviors that might be expected with increases in dopamine activity followint a moderately high acute dose of cocaine $(30 \mathrm{mg} / \mathrm{kg})$.

The present findings are both similar to and different from previous studies, which have examined the effects of chronic gestational cocaine treatment on maternal behavior and aggression. Several chronic cocaine treatment studies $[6,7,9,10,30]$ reported few or no significant effects of gestational cocaine treatment on most established maternal behaviors (except maternal aggression) following cessation of treatment. They also reported no significant increases in locomotor activity that could account for deficits in onset of maternal behavior. It could be argued that acute cocaine interfered with maternal behavior simply because it increased activity and stereotypical behaviors. While that is possible, and likely has some effects, we have previously reported that just increasing locomotor behavior and stereotypies in rats does not significantly alter their ability to ge maternal [21]. All dams 
displayed maternal behavior but the timing and sequence of behaviors were altered, as seen in previous studies using chronic gestational treatment [20].

One of the most striking differences between the present study and previous chronic gestational cocaine treatment paradigms is that chronic treatment $(30 \mathrm{mg} / \mathrm{kg})$ results in increased maternal aggression towards an intruder on PPD 6 and 8 [20-22] while acute cocaine treatment decreases aggression using the same testing procedures, during the same lactation period, regardless of sex of the intruder. There is a clear dose-response effect on aggression following acute treatment. It is apparent that activity-related changes were not responsible for the decreased aggression. Often dams would move aggressively toward the intruder and then suddenly veer off to the side and remain still. The higher-dose cocaine groups also allowed more attacks on their litters than did the low-dose and sal/con groups, often standing to the side and watching the intruder attack. Since normal maternal aggression in rat dams may be partially dependent upon suckling stimulation or ventral mammary sensory stimulation $[31,32]$, we must take into account the possibility that the pups of the dams in the higher-dose cocaine groups did not suckle as much during the first $48 \mathrm{~h}$ of the lactation period, which may have altered the dams' aggressive behavior.

We have previously suggested that cocaine-induced changes in oxytocin levels in specific brain areas may underlie behavioral changes following chronic cocaine treatment and have provided some evidence that supports this hypothesis [20-22, 27]. In the present study, the dams were last injected on the morning of PPD 10, so we could only assess any effects on oxytocin levels that might have resulted from the four cumulative treatments. No significant effects on oxytocin levels were found. However, since we did not sacrifice the dams directly following testing on each postpartum day $(1,3,6,10)$ we do not know if single acute injections at each of these time periods might have altered oxytocin levels in any of the brain areas analyzed. Preliminary data (unpublished) suggests this may be the case. Alternatively, effects of cocaine on maternal behavior and aggression following chronic treatment $[6,20-$ 22] may be the result of long-term changes in oxytocin parameters (receptors, binding) or other long-term biochemical changes in neurotransmitter systems that would not be expected following acute treatment. The fact that acute cocaine treatment altered both the onset and established maternal behavior unlike chronic gestational cocaine, which alters the onset $[7$, 20-22] but not established maternal behavior, suggests that, with respect to pup-directed maternal behavior, different mechanisms may underlie the two types of treatments.

This study demonstrates that acute cocaine disrupts maternal behavior and aggression in a dose-dependent manner. How many of the observed changes were due to cocaine-induced activity increases or in other neurotransmitter-related changes is unclear. This study confirms previous reports $[7,23,30]$ that a single dose of cocaine interferes with maternal behavior, and extends these findings by demonstrating that multiple acute doses result in significantly less protectiveness of pups in the presence of an intruder by PPD 6 and 10 . Both chronic and acute cocaine treatment result in deleterious effects on the mother's behavior, with the offspring neglect and or abuse regardless of the injection paradigm. This work highlights the need for a clearer understanding of the mechanisms underlying the effects of maternal cocaine use and for a greater awareness of the possible consequences of any type of cocaine abuse in the general human population.

\section{Acknowledgments}

I would like to thank Dr. George Mason and the UNC MHCRC No. MH33127 for their technical assistance. This research was supported by an NIH grant (NIDA, DA R29-08456 awarded to J.M.J.). K.E. Meter was supported by a Stanley Foundation fellowship and C.J. Nelson and D.A. Lubin were supported by a NIH predoctoral drug training grant (No. DA07244). 


\section{References}

1. Ball SA, Mayes LC, DeTeso JARS. Maternal attentiveness of cocaine abusers during child-based assessments. Am J Addict. 1997; 6:135-143. [PubMed: 9134075]

2. Dembo R, Williams L, Wish ED, Berry E, Getreu A, Washburn M, Schmeidler J. Examination of the relationships among drug use, emotional/psychological problems, and crime among youths entering a juvenile detention center. Int J Addict. 1990; 25:1301-1340. [PubMed: 2090629]

3. Burns K, Chethik L, Burns WJ, Clark R. Dyadic disturbances in cocaine-abusing mothers and their infants. J Clin Psychol. 1991; 47:316-319. [PubMed: 2030140]

4. Murphy JM, Jellinik M, Quinn D, Smith G, Poitrast FG, Goshko M. Substance abuse and serious child mistreatment: Prevalence, risk and outcome in a court sample. Child Abuse Negl. 1991; 15:197-211. [PubMed: 2043972]

5. Kelly SJ, Walsh JH, Thompson K. Birth outcomes, health problems, and neglect with prenatal exposure to cocaine. Pediatr Nurs. 1991; 17:130-136. [PubMed: 1712934]

6. Heyser CJ, Molina VA, Spear LP. A fostering study of the effects of prenatal cocaine exposure. I. Maternal behaviors. Neurobehav Toxicol Teratol. 1992; 14:415-422.

7. Kinsley CH, Turco D, Bauer A, Beverly M, Wellman J, Graham AL. Cocaine alters the onset and maintenance of maternal behavior in lactating rats. Pharmacol Biochem Behav. 1994; 47:857-864. [PubMed: 8029256]

8. Peeke HV, Dark KA, Salamy A, Salfi M, Shah SN. Cocaine exposure prebreeding to weaning: Maternal and offspring effects. Pharmacol Biochem Behav. 1994; 48:403-410. [PubMed: 8090807]

9. Vernotica EM, Lisciotto CA, Rosenblatt JS, Morrell JI. Cocaine transiently impairs maternal behavior in the rat. Behav Neurosci. 1996; 110:315-323. [PubMed: 8731058]

10. Sobrian SK, Burton LE, Robinson NL, Ashe WK, James H, Stokes KL, Turner LM. Neurobehavioral and immunological effects of prenatal cocaine exposure in the rat. Pharmacol Biochem Behav. 1990; 35:617-629. [PubMed: 2160088]

11. Fahrbach SE, Morrell JI, Pfaff DW. Oxytocin induction of short-latency maternal behavior, in nulliparous, estrogen-primed female rats. Horm Behav. 1984; 18:267-286. [PubMed: 6489942]

12. Pedersen CA, Ascher JA, Monroe YL, Prange AJ. Oxytocin induces behavior in virgin female rats. Science. 1982; 216:648-649. [PubMed: 7071605]

13. Pedersen CA, Prange AJ. Induction of maternal behavior in virgin rats after intracerebroventricular administration of oxytocin. Proc Natl Acad Sci USA. 1979; 76:6661-6665. [PubMed: 293752]

14. Fahrbach SE, Morrell JI, Pfaff DW. Possible role for endogenous oxytocin in estrogen-facilitated maternal behavior in rats. Neuroendocrinology. 1985; 40:526-532. [PubMed: 4010891]

15. Pedersen CA, Caldwell JD, Walker CH, Ayers G, Mason GA. Oxytocin activates the postpartum onset of rat maternal behavior in the ventral tegmental and medial preoptic areas. Behav Neurosci. 1994; 108:1163-1171. [PubMed: 7893408]

16. Van Leengoed E, Kerker E, Swanson HH. Inhibition of postpartum maternal behavior in the rat by injecting an oxytocin antagonist into the cerebral ventricles. J Endocrinol. 1987; 112:275-282. [PubMed: 3819639]

17. Kozlowski, GP.; Nilaver, G. Localization of neurohypophyseal hormones in the mammalian brain. In: de Wied, D.; Gispen, WH.; van Wimersma Greidanus, Tj B., editors. Neuropeptides and Behavior: The Neurohypophyseal Hormones. Vol. vol 2. Oxford: Pergamon Press; 1986. p. 23-38.

18. Insel TR, Harbaugh CR. Lesions of the hypothalamic paraventricular nucleus disrupt the initiation of maternal behavior. Physiol Behav. 1989; 45:1033-1041. [PubMed: 2780864]

19. Numan M, Corodimas KP. The effects of paraventricular hypothalamic lesions on maternal behavior in rats. Physiol Behav. 1985; 35:415-425.

20. Johns JM, Noonan LR, Zimmerman LI, Li L, Pedersen CA. Effects of chronic and acute cocaine treatment on the onset of maternal behavior and aggression in Sprague-Dawley rats. Behav Neurosci. 1994; 108:107-112. [PubMed: 8192835]

21. Johns JM, Faggin BM, Noonan LR, Li L, Zimmermann LI, Pedersen CA. Chronic cocaine treatment decreases oxytocin levels in the amygdala and increases aggression in Sprague-Dawley rats (abstract). Soc Neurosci Abstr. 1995; 21:1954. 
22. Johns JM, Noonan LR, Zimmerman LI, Li L, Pedersen CA. Effects of short and long-term withdrawal from gestational cocaine on maternal behavior and aggression in Sprague-Dawley rats. Dev Neurosci. 1997; 19:368-374. [PubMed: 9215883]

23. Zimmerberg B, Grey MS. The effects of cocaine on maternal behaviors in the rat. Physiol Behav. 1992; 52:379-384. [PubMed: 1523266]

24. Konig, JFR.; Klippel, RA. The Rat Brain: A Stereotaxic Atlas of the Forebrain and Lower Parts of the Brain Stem. New York: Krieger; 1963.

25. Hadley, ME. Endocrinology. Englewood Cliffs: Prentice-Hall; 1992.

26. Brown, RE. An Introduction to Neuroendocrinology. New York: Cambridge University Press; 1994.

27. Johns JM, Lubin DA, Walker CH, Meter KE, Mason GA. Chronic gestational cocaine treatment decreases oxytocin levels in the medial preoptic area, ventral tegmental area and hippocampus in Sprague-Dawley rats. Neuropeptides. 1997; 31:439-443. [PubMed: 9413020]

28. Kovacs GL, Sarnyai Z, Babarczi E, Szabo G, Telegdy G. The role of oxytocin-dopamine interactions in cocaine-induced locomotor hyperactivity. Neuropharmacology. 1990; 29:365-368. [PubMed: 2160623]

29. Vernotica EM, Rosenblatt JS, Morrell JI. Acute cocaine alters all components of established postpartum maternal behavior in the rat (abstract 738.6). Soc Neurosci Abstr. 1996; 22:1884.

30. Nelson CJ, Ayers A, Meter KE, Walker CH, Johns JM. Chronic cocaine treatment alters maternal behavior in a dose response manner in Sprague Dawley rats (abstract 738.8). Soc Neurosci Abstr. 1996; $22: 1884$.

31. Mayer AD, Carter L, Jorge WH, Mota MJ, Tannu S, Rosenblatt JS. Mammary stimulation and maternal aggression in rodents: Thelectomy fails to reduce pre- or postpartum aggression in rats. Horm Behav. 1987; 21:501-510. [PubMed: 3428888]

32. Stern JM, Levine S. Pituitary-adrenal activity in the postpartum rat in the absence of suckling stimulation. Horm Behav. 1972; 3:237-246. [PubMed: 4376124] 


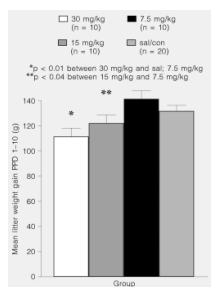

Fig. 1.

Acute postpartum cocaine treatment in rat dams reduces litter weight by PPD 10. 

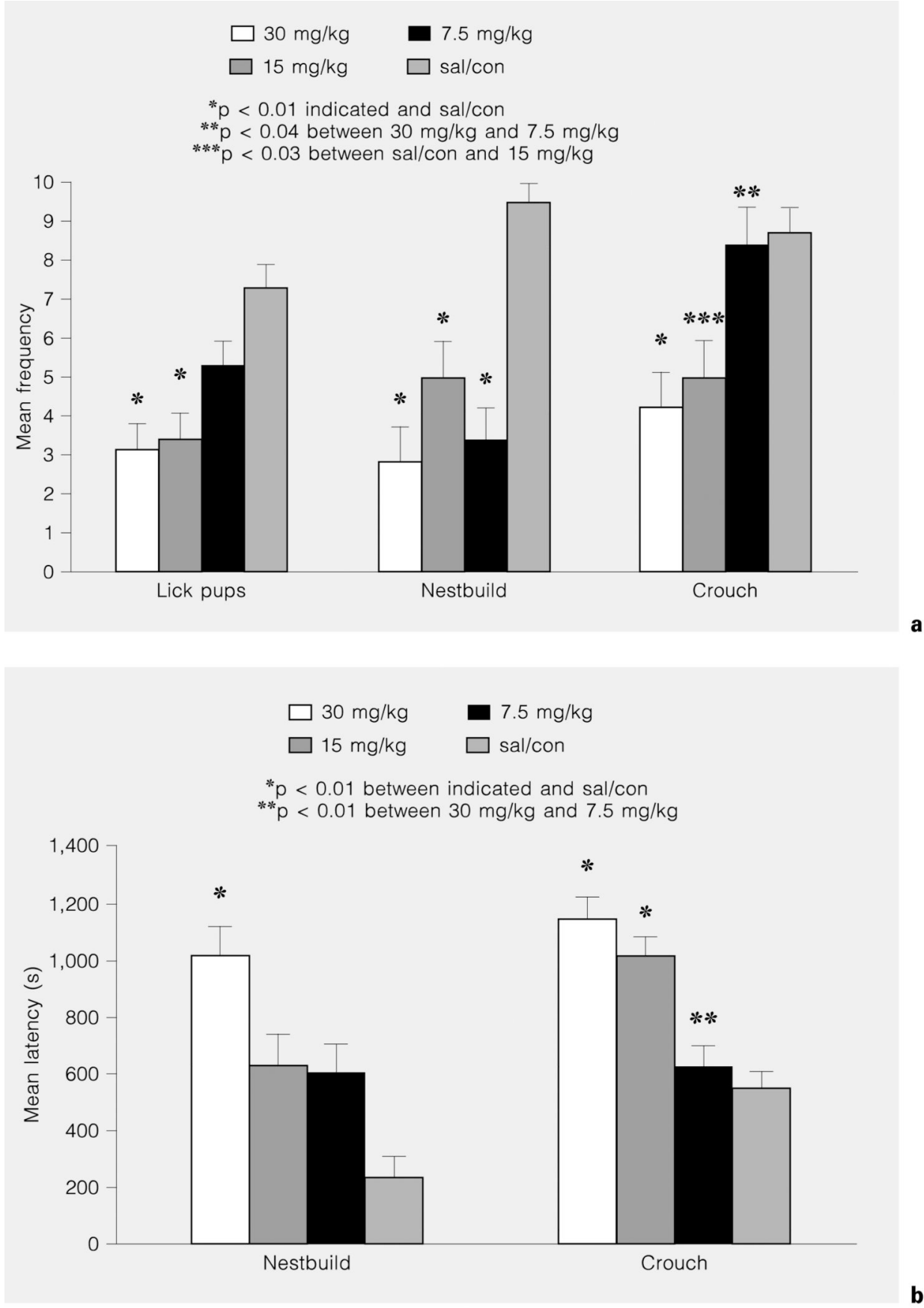

Fig. 2.

Frequency of nestbuilding, crouching and pup licking (a) and latency to nestbuild and crouch (b) are reduced in cocaine-treated dams in a dose-dependent manner on PPD 1 and PPD 3. 

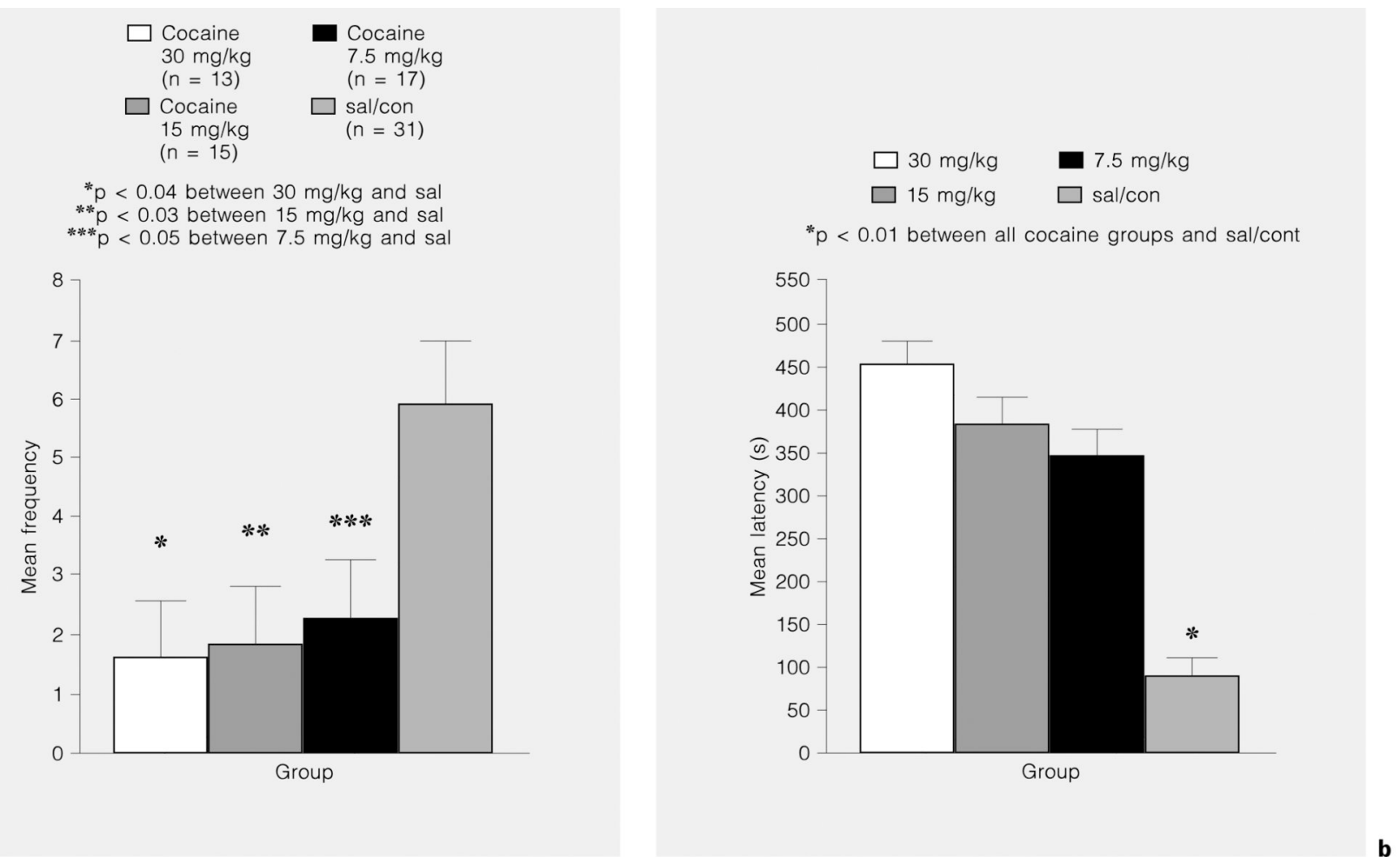

Fig. 3.

Cocaine treatment decreases the frequency of (a) and latency to (b) attack intruders in an aggression test on PPD 6 and PPD 10. 


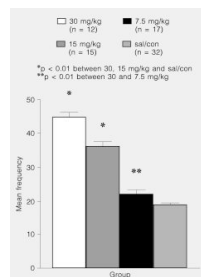

Fig. 4.

Acute postpartum cocaine treatment in rat dams increases the frequency of rearing and sniffing on PPD 6 and PPD 10. 